\title{
Disruption of spindle checkpoint function in rats following 28 days of repeated administration of renal carcinogens
}

\author{
Masayuki Kimura ${ }^{1,2}$, Sayaka Mizukami1,2, Yousuke Watanabe ${ }^{1,2}$, Yasuko Hasegawa-Baba1, \\ Nobuhiko Onda1 ${ }^{1}$ Toshinori Yoshida1 and Makoto Shibutani ${ }^{1}$ \\ 'Laboratory of Veterinary Pathology, Tokyo University of Agriculture and Technology, \\ 3-5-8 Saiwai-cho, Fuchu-shi, Tokyo 183-8509, Japan \\ ${ }_{2}^{2}$ athogenetic Veterinary Science, United Graduate School of Veterinary Sciences, Gifu University, \\ 1-1 Yanagido, Gifu-shi, Gifu 501-1193, Japan
}

(Received September 19, 2015; Accepted November 4, 2015)

\begin{abstract}
We previously reported that 28-day exposure to hepatocarcinogens that facilitate cell proliferation specifically alters the expression of $\mathrm{G}_{1} / \mathrm{S}$ checkpoint-related genes and proteins, induces aberrant early expression of ubiquitin $\mathrm{D}$ (UBD) at the $\mathrm{G}_{2}$ phase, and increases apoptosis in the rat liver, indicating $\mathrm{G}_{1} / \mathrm{S}$ and spindle checkpoint dysfunction. The present study aimed to determine the time of onset of carcinogen-specific cell-cycle disruption after repeated administration of renal carcinogens for up to 28 days. Rats were orally administered the renal carcinogens nitrofurantoin (NFT), 1-amino-2,4-dibromoantraquinone (ADAQ), and 1,2,3-trichloropropane (TCP) or the non-carcinogenic renal toxicants 1-chloro-2-propanol, triamterene, and carboxin for 3, 7 or 28 days. Both immunohistochemical singlemolecule analysis and real-time RT-PCR analysis revealed that carcinogen-specific expression changes were not observed after 28 days of administration. However, the renal carcinogens ADAQ and TCP specifically reduced the number of cells expressing phosphorylated-histone H3 at Ser10 in both UBD ${ }^{+}$cells and proliferating cells, suggestive of insufficient UBD expression at the M phase and early transition of proliferating cells from the $\mathrm{M}$ phase, without increasing apoptosis, after 28 days of administration. In contrast, NFT, which has marginal carcinogenic potential, did not induce such cellular responses. These results suggest that it may take 28 days to induce spindle checkpoint dysfunction by renal carcinogens; however, induction of apoptosis may not be essential. Thus, induction of spindle checkpoint dysfunction may be dependent on carcinogenic potential of carcinogen examined, and marginal carcinogens may not exert sufficient responses even after 28 days of administration.
\end{abstract}

Key words: Cell proliferation, Renal carcinogen, Spindle checkpoint, Ubiquitin D, Apoptosis

\section{INTRODUCTION}

One of the most reliable methods to evaluate the carcinogenicity of chemicals involves exposing rodent animals to test compounds for 1.5 or 2 years. However, these bioassays are time consuming and expensive, and involve the use of hundreds of animals. To resolve these problems, alternative methods have been developed, such as the two-stage carcinogenesis model (Tamano, 2010) and genetically modified animals produced by transgenic or gene targeting technologies (Eastin, 1998). However, these methods are also laborious and expensive, and have limited target organs. Although toxicogenomic approaches for the prediction of carcinogenic potential in each target organ may be promising (Jonker et al., 2009; Matsumoto et al., 2014), these methods also require integrative methodologies between different laboratories sharing expression databases. Therefore, the development of rapid and inexpensive assays for evaluating or predicting the carcinogenic potential of chemicals based on the molecular responses to the carcinogens in the target organs would be advantageous.

We have previously analyzed cell-cycle proteins in a study of 28-day repeated treatment with carcinogens. We found that carcinogens facilitating cell proliferation in carcinogenic target cells also induced aberrant expression of cell-cycle proteins involved in the activation of $\mathrm{G}_{1} / \mathrm{S}$ and $\mathrm{G}_{2} / \mathrm{M}$ checkpoint functions to cause cell-cycle

Correspondence: Makoto Shibutani (E-mail: mshibuta@cc.tuat.ac.jp) 
arrest and apoptosis irrespective of the target organ after a 28-day administration period (Taniai et al., 2012a, 2012b; Yafune et al., 2013a, 2013b). In addition, we found that such carcinogens typically induced an aberrant shift in the expression of ubiquitin D (UBD), a spindle checkpoint inhibitor (Herrmann et al., 2007; Lim et al., 2006), at the $G_{2}$ phase in carcinogenic target cells, indicating spindle checkpoint dysfunction at the $\mathrm{M}$ phase (Taniai et al., 2012b; Kimura et al., 2015a). These results suggest that carcinogens facilitating cell proliferation in target cells induce aberrant cell-cycle control, including disruption of spindle checkpoint function, which may be a common cellular response to carcinogens. Furthermore, we have also recently found that some hepatocarcinogens specifically caused the downregulation of $R b l 2$, upregulation of $M d m 2$, and increase the number of phosphorylated-E3 ubiquitin-protein ligase MDM2 (p-MDM2)+ cells, suggestive of disruption to $\mathrm{G}_{1} / \mathrm{S}$ checkpoint function, as well as spindle checkpoint dysfunction, only after 28 days of administration (Kimura et al., 2015a). Moreover, in a study of repeated administration of hepatocarcinogens for up to 90 days, hepatocarcinogen carbadox caused disruption of spindle checkpoint function after 90 days of administration, while this compound did not facilitate cell proliferation at this time point (Kimura et al., 2015b). These results suggest that carcinogen-specific disruption of spindle checkpoint function may be induced after 28 or 90 days of administration of hepatocarcinogens, which may be induced ahead of facilitation of cell proliferation at initial stage of carcinogenesis. However, it is not clear whether the time of onset of aberrant cell-cycle regulation specifically observed with hepatocarcinogens could be applied to carcinogens targeting other organs.

The present study aimed to determine the time of onset of carcinogen-specific disruption of cell-cycle regulation during a time course of repeated administration of renal carcinogens. For this purpose, rats were repeatedly administered renal carcinogens or non-carcinogenic renal toxicants for up to 28 days, and the time course response in cell proliferation activity, expression of $\mathrm{G}_{1} / \mathrm{S}, \mathrm{G}_{2} / \mathrm{M}$, and spindle checkpoint-related molecules, and apoptosis were examined using immunohistochemistry and/or real-time reverse transcription polymerase chain reaction (RT-PCR).

\section{MATERIALS AND METHODS}

\section{Chemicals}

Nitrofurantoin (NFT; CAS No. 67-20-9, purity >98.0\%) and triamterene (TAT; CAS No. 396-01-0, purity $>98.0 \%$ ) were purchased from Tokyo Chemical Industry
Co. Ltd. (Tokyo, Japan). 1-Amino-2,4-dibromoantraquinone (ADAQ; CAS No. 81-49-2, purity $\geq 97 \%$ ), carboxin (CBX; CAS No. 5234-68-4, purity $\geq 95 \%$ ), 1-chloro2-propanol (CP; CAS No. 127-00-4, purity $75 \%$ to $76 \%$ 1-chloro-2-propanol; $24 \%$ to $25 \%$ 2-chloro-1-propanol), 1,2,3-trichloropropane (TCP; CAS No. 96-18-4, purity $\geq 99 \%$ ) were purchased from Wako Pure Chemicals Industries (Osaka, Japan). Corn oil was purchased from Hayashi Chemicals Co. Ltd. (Tokyo, Japan).

\section{Animal experiments}

Five-week-old male F344/NSlc rats were purchased from Japan SLC, Inc. (Shizuoka, Japan), and acclimatized to a powdered basal diet (CRF-1; Oriental Yeast Co., Tokyo, Japan) and tap water ad libitum for one week. Rats were housed in plastic cages with paper chip in a barrier-maintained animal room under standard conditions (room temperature, $23 \pm 3^{\circ} \mathrm{C}$; relative humidity, $50 \pm 20 \% ; 12-\mathrm{hr}$ light/dark cycle).

In the present study, animals were administered renal carcinogens (NFT, ADAQ, or TCP) or non-carcinogenic renal toxicants (CP, TAT, or CBX). Animals were repeatedly administered test chemicals for 3, 7 and 28 days. After administration, cell proliferation activity, expression of cell cycle-related molecules, and apoptosis were examined using immunohistochemistry and/or real-time RT-PCR.

NFT, ADAQ, and TCP were selected as renal carcinogens (National Toxicology Program [NTP], 1989; NTP, 1993a; NTP, 1996) and CP, TAT, and CBX were selected as non-carcinogenic renal toxicants (NTP, 1993b; NTP, 1998; US Environmental Protection Agency [USEPA], 2004).

Animals were divided into seven groups based on initial body weights and administered NFT in basal diet ( $\mathrm{n}$ $=33)$, ADAQ $(25,000 \mathrm{ppm})$ in basal diet $(\mathrm{n}=33)$, TCP (125 mg/kg body weight) daily by gavage in corn oil ( $\mathrm{n}$ $=33)$, CP $(3,300 \mathrm{ppm})$ in drinking water $(\mathrm{n}=30)$, TAT $(1,200 \mathrm{ppm})$ in basal diet $(\mathrm{n}=30)$ or $\mathrm{CBX}(2,000 \mathrm{ppm})$ in basal diet $(n=30)$ for 3,7 or 28 days. In the NFT group, the initial dose was set at 5,000 ppm in the diet. However, as the general condition of the animals worsened, the dose was reduced to 4,000 ppm after 9 days from starting administration and 3,000 ppm after 14 days. Untreated controls $(n=30)$ were maintained on the basal diet and tap water without any treatment during the experimental period. After the 3, 7 or 28 days of treatment, one third $(n=10$ or 11$)$ of the animals in each group were euthanized by exsanguination from the abdominal aorta under deep anesthesia with $\mathrm{CO}_{2} / \mathrm{O}_{2}$ and kidneys were removed.

The dose levels of NFT, ADAQ, and TCP, even after 
Disruption of spindle checkpoint function by renal carcinogens in rats

the dose change in case of NFT, have been shown to induce kidney tumors in rats (NTP, 1989; NTP, 1993a; NTP, 1996). The dose levels of CP, TAT, and CBX induced nephrotoxicity after a 13- or 14-week administration in rats (NTP, 1993b; NTP, 1998; USEPA, 2004).

All animal experiments were conducted in accordance with the "Guidelines for Proper Conduct of Animal Experiments" (Science Council of Japan, June 1, 2006), and the animal protocols were reviewed and approved by the Animal Care and Use Committee of the Tokyo University of Agriculture and Technology. All efforts were made to minimize animal suffering.

\section{Histology and immunohistochemistry}

Three-micrometer sections of paraffin-embedded tissues from the kidney were stained with hematoxylin and eosin for histopathological examination, or subjected to immunohistochemistry. Immunohistochemistry of kidney sections was performed using the Vectastain ${ }^{\circledR}$ Elite ABC Kit (Vector Laboratories Inc., Burlingame, CA, USA) with 3,3'-diaminobenzidine $/ \mathrm{H}_{2} \mathrm{O}_{2}$ as the chromogen and the following antibodies: Ki-67, a marker of cell proliferation expressing in the nucleus during the $G_{1}$ to $M$ phase of the cell cycle (Scholzen and Gerdes, 2000), phosphorylated histone $\mathrm{H} 3$ (p-Histone $\mathrm{H} 3$ ), acting on chromosome condensation at the early $\mathrm{M}$ phase (Hirota et al., 2005), topoisomerase II alpha (TOP2A), acting on DNA decatenation at $\mathrm{G}_{2} / \mathrm{M}$ phase (Mattila et al., 2007), UBD, a molecule that leads to chromosomal instability through reduction in kinetochore localization of checkpoint proteins, such as mitotic arrest deficient-2 (MAD2), during the $\mathrm{G}_{2} / \mathrm{M}$ phase (Herrmann et al., 2007; Lim et al., 2006), and p-MDM2 (Ser 166), a p53 downstream molecule that facilitates degradation of p53 (Malmlöf et al., 2007; Mayo and Donner, 2002). Antigen retrieval conditions and the concentrations of each antibody are shown in Supplementary Table 1. Immunostained sections were counterstained with hematoxylin for microscope examination. Endogenous peroxidase activity was blocked with $0.3 \%$ hydrogen peroxide.

For evaluation of apoptosis, the terminal deoxynucleotidyl transferase dUTP nick end labeling (TUNEL) assay was performed using the ApopTag In Situ Apoptosis Detection Kit (Millipore Corporation, Billerica, MA, USA) according to the manufacturer's protocol. Briefly, deparaffinized sections were treated with $20 \mu \mathrm{g} / \mathrm{mL}$ proteinase $\mathrm{K}$ for $15 \mathrm{~min}$ at room temperature. Endogenous peroxidase activity was blocked with $3.0 \%$ hydrogen peroxide. Color development and counter staining were as described above for immunohistochemistry.

To estimate the ratio of $\mathrm{UBD}^{+}$cells colocalized with
TOP2A or $\mathrm{p}-$ Histone $\mathrm{H} 3$ to the total number of $\mathrm{UBD}^{+}$ cells, double immunohistochemistry of UBD with TOP2A or p-Histone H3 was conducted. For this purpose, the Vectastain ${ }^{\circledR}$ Elite ABC Kit (Vector Laboratories Inc.) with 3,3'-diaminobenzidine was used to visualize UBD and the Vectastain ${ }^{\circledR}$ ABC-AP kit (Vector Laboratories Inc.) with Vector Red Alkaline Phosphate Substrate Kit I (Vector Laboratories Inc.) was used to visualize TOP2A and p-Histone $\mathrm{H} 3$.

\section{Analysis of immunoreactivity}

In our previous study, all tested renal carcinogens increased cells expressing cell cycle proteins as candidate prediction markers of carcinogenicity in analysis of the outer stripe of the outer medulla (OSOM), while $p$-nitrobenzoic acid, a non-carcinogenic renal toxicant, also increased cells expressing cell cycle proteins in analysis of the whole cortical area and OSOM (Taniai et al., 2012a, 2012b). Therefore, only OSOM areas were selected for analysis of immunoreactive cells to avoid detecting false-positive responses in the present study.

The immunoreactive cells for Ki-67, p-Histone H3, TOP2A, UBD, and p-MDM2 and TUNEL ${ }^{+}$apoptotic cells were counted in 10 randomly selected areas per animal ( 5 areas per kidney) at $400 \times$ magnification, avoiding areas of connective tissues and vasculature. Immunoreactive renal proximal and distal tubular epithelial cells in OSOM were counted visually, and the total number of renal tubular epithelial cells in OSOM in the micrographs was separately counted using the image binarization method in the Win-ROOF image analysis and measurement software (version 6.4.2., Mitani Corporation, Fukui, Japan). Then, the percentage of total immunoreactive cells was estimated in each animal.

\section{Real-time RT-PCR analysis}

To investigate the expression levels of representative cell cycle-related genes in the area of OSOM, mRNA expression analysis was performed using the StepOnePlus ${ }^{\text {TM }}$ Real-time RT-PCR System (Life Technologies, Carlsbad, CA, USA) with the SYBR ${ }^{\circledR}$ Green PCR Master Mix (Life Technologies). The forward and reverse primers listed in Supplementary Table 2 were designed using the Primer Express 3.0 software (Life Technologies). Using the threshold cycle values of actin, beta $(A c t b)$ or glyceraldehyde 3-phosphate dehydrogenase (Gapdh) in the same sample as the endogenous control, the relative differences in gene expression were calculated using the $2^{-\Delta \Delta C}{ }_{T}$ method (Livak and Schmittgen, 2001). 
M. Kimura et al.

\section{Statistical analysis}

All data are represented as mean \pm S.D. Numerical data were analyzed by the Bartlett's test for the homogeneity of variance. If there was no significant difference in variance, Dunnett's test was performed for comparison between the groups. If a significant difference was found in variance, Steel's test was performed. All numerical data of the treatment groups were compared with those of untreated controls.

\section{RESULTS}

\section{Body and kidney weights}

At day 3, the final body weights were significantly decreased in the NFT, TCP, and CP groups compared with untreated controls (Table 1). The absolute kidney weight of rats in the CP group was significantly lower than that of untreated controls. The relative kidney weights of rats in the NFT, ADAQ, TCP, and CP groups were significantly higher than that of untreated controls.

At day 7, the final body weights were significantly decreased in the NFT, TCP, and CP groups compared with untreated controls (Table 1). The absolute kidney weights of rats in the NFT, TCP, CP, and TAT groups were significantly lower than that of untreated controls. The relative kidney weights of rats in the NFT, TCP, and CP groups were significantly higher than that of untreated controls.

At day 28, the final body weights were significantly decreased in the NFT, TCP, and CP groups compared with untreated controls (Table 1). The absolute kidney weights of rats in the NFT and CP groups were significantly lower than that of untreated controls. The relative kidney weights of rats in the NFT, ADAQ, TCP, CP, and $\mathrm{CBX}$ groups were significantly higher than that of untreated controls.

Table 1. Initial and final body weights and kidney weight of rats after treatment with renal carcinogens, or noncarcinogenic renal toxicants.

\begin{tabular}{|c|c|c|c|c|c|}
\hline \multirow{2}{*}{ Group } & \multirow{2}{*}{$\begin{array}{l}\text { Number of } \\
\text { animals }\end{array}$} & \multirow{2}{*}{$\begin{array}{l}\text { Initial body } \\
\text { weight }(\mathrm{g})\end{array}$} & \multirow{2}{*}{$\begin{array}{l}\text { Final body } \\
\text { weight (g) }\end{array}$} & \multicolumn{2}{|c|}{ Kidney weight } \\
\hline & & & & Absolute (g) & Relative (g/100 g BW) \\
\hline \multicolumn{6}{|l|}{ Day 3} \\
\hline CONT & 10 & $131.7 \pm 8.7^{\mathrm{a}}$ & $150.6 \pm 10.1$ & $1.22 \pm 0.09$ & $0.81 \pm 0.03$ \\
\hline NFT & 11 & $131.1 \pm 9.9$ & $122.8 \pm 11.7^{* *}$ & $1.14 \pm 0.09$ & $0.94 \pm 0.09 * *$ \\
\hline ADAQ & 11 & $130.2 \pm 9.8$ & $143.9 \pm 9.2$ & $1.25 \pm 0.07$ & $0.87 \pm 0.04^{*}$ \\
\hline $\mathrm{TCP}$ & 11 & $132.0 \pm 11.4$ & $124.5 \pm 9.5^{* *}$ & $1.19 \pm 0.10$ & $0.96 \pm 0.04 * *$ \\
\hline $\mathrm{CP}$ & 10 & $131.9 \pm 7.0$ & $124.8 \pm 7.9^{* *}$ & $1.09 \pm 0.09 * *$ & $0.87 \pm 0.05^{*}$ \\
\hline TAT & 10 & $132.3 \pm 8.5$ & $149.1 \pm 8.7$ & $1.21 \pm 0.08$ & $0.81 \pm 0.02$ \\
\hline $\mathrm{CBX}$ & 10 & $131.8 \pm 6.3$ & $148.8 \pm 8.2$ & $1.19 \pm 0.08$ & $0.80 \pm 0.02$ \\
\hline \multicolumn{6}{|l|}{ Day 7} \\
\hline CONT & 10 & $133.8 \pm 8.5$ & $176.2 \pm 10.8$ & $1.43 \pm 0.08$ & $0.81 \pm 0.04$ \\
\hline NFT & 11 & $133.9 \pm 11.7$ & $116.9 \pm 8.8^{* *}$ & $1.12 \pm 0.10^{* *}$ & $0.96 \pm 0.07 * *$ \\
\hline ADAQ & 11 & $133.3 \pm 9.6$ & $168.8 \pm 11.6$ & $1.40 \pm 0.14$ & $0.83 \pm 0.03$ \\
\hline $\mathrm{TCP}$ & 11 & $134.7 \pm 8.2$ & $133.9 \pm 10.7^{* *}$ & $1.24 \pm 0.10^{* *}$ & $0.93 \pm 0.03 * *$ \\
\hline $\mathrm{CP}$ & 10 & $135.6 \pm 8.2$ & $130.4 \pm 7.0 * *$ & $1.14 \pm 0.10 * *$ & $0.87 \pm 0.04 * *$ \\
\hline TAT & 10 & $133.0 \pm 10.0$ & $168.2 \pm 11.7$ & $1.31 \pm 0.13^{*}$ & $0.78 \pm 0.03$ \\
\hline $\mathrm{CBX}$ & 10 & $132.6 \pm 7.8$ & $171.2 \pm 11.3$ & $1.35 \pm 0.07$ & $0.79 \pm 0.03$ \\
\hline \multicolumn{6}{|l|}{ Day 28} \\
\hline CONT & 10 & $118.6 \pm 6.8$ & $240.9 \pm 5.7$ & $1.66 \pm 0.08$ & $0.69 \pm 0.03$ \\
\hline NFT & 11 & $119.5 \pm 6.2$ & $131.0 \pm 9.7^{* *}$ & $1.31 \pm 0.14^{* *}$ & $1.00 \pm 0.10^{* *}$ \\
\hline ADAQ & 11 & $119.5 \pm 6.1$ & $228.9 \pm 16.3$ & $1.76 \pm 0.13$ & $0.77 \pm 0.03 * *$ \\
\hline $\mathrm{TCP}$ & 11 & $121.0 \pm 6.6$ & $173.4 \pm 6.4^{* *}$ & $1.55 \pm 0.07$ & $0.89 \pm 0.03 * *$ \\
\hline $\mathrm{CP}$ & 10 & $119.0 \pm 7.4$ & $177.1 \pm 13.5^{* *}$ & $1.54 \pm 0.09 *$ & $0.87 \pm 0.03 * *$ \\
\hline TAT & 10 & $119.5 \pm 6.4$ & $234.8 \pm 10.8$ & $1.61 \pm 0.12$ & $0.68 \pm 0.03$ \\
\hline $\mathrm{CBX}$ & 10 & $118.9 \pm 8.8$ & $230.1 \pm 13.3$ & $1.71 \pm 0.13$ & $0.74 \pm 0.02 * *$ \\
\hline
\end{tabular}

Abbreviations: ADAQ, 1-amino-2,4-dibromoantraquinone; CBX, carboxin; CONT, untreated controls; CP, 1-chloro-2-propanol; NFT, nitrofurantoin; TAT, triamterene; TCP, 1,2,3-trichloropropane.

a Values are expressed as mean \pm S.D.

$* P<0.05, * * P<0.01$ vs. untreated controls (Dunnett's or Steel's test). 
Disruption of spindle checkpoint function by renal carcinogens in rats

\section{Histopathological changes}

NFT treatment induced hyaline droplet degeneration of proximal tubules in the cortex from day 3 of treatment, and scattered proximal tubular regeneration in the cortex and OSOM at day 28. Similar to a previous report (NTP, 1996), ADAQ treatment induced hyaline droplet degeneration of proximal tubules in the cortex from day 3 of treatment, and proximal tubular pigmentation in the OSOM and scattered tubular regeneration in the cortex and OSOM at day 28. TCP treatment induced proximal tubular cell karyomegaly accompanied with diffuse regenerative hyperplasia in the OSOM from day 3 , similar to previous report (NTP, 1993a). CP treatment induced marginal hyaline droplet degeneration of proximal tubules in the cortex at day 28. TAT treatment induced hyaline droplet degeneration of proximal tubules in the cortex, and scattered tubular regeneration in the cortex and OSOM at day 28, similar to previous report (NTP, 1993b). CBX treatment induced scattered tubular regeneration in the cortex and OSOM, and hyaline cast in the Henle's thin segment and collecting tubules, accompanied with diffuse regeneration of collecting tubules at day 28 .

\section{Distribution of immunoreactive cells and apoptotic cells}

Ki-67, p-Histone H3, TOP2A, and p-MDM2 were immunolocalized in the nucleus of tubular epithelial cells, and UBD was immunolocalized in the cytoplasm or mitotic spindle of tubular epithelial cells (Figs. 1-3). TUNEL $^{+}$apoptotic cells were also observed in tubular epithelial cells (Figs. 1-3). Ki-67+, p-Histone $\mathrm{H} 3^{+}$, TOP $2 \mathrm{~A}^{+}, \mathrm{UBD}^{+}$, and TUNEL ${ }^{+}$cells were evenly distributed in the renal tubules within the kidney. With regard to p-MDM2, immunoreactive cells were predominantly observed in distal tubular epithelial cells.

At day 3, the number of $\mathrm{Ki}-67^{+}$cells significantly increased in the NFT, TCP, and CBX groups, and significantly decreased in the ADAQ and TAT groups compared with untreated controls (Fig. 1A). The number of p-Histone $\mathrm{H}^{+}$cells significantly increased in the NFT and TCP groups, and significantly decreased in the TAT group compared with untreated controls (Fig. 1B). The number of TOP $2 \mathrm{~A}^{+}$cells significantly increased in the NFT, TCP, $\mathrm{CP}$, and $\mathrm{CBX}$ groups, and significantly decreased in the ADAQ and TAT groups compared with untreated controls (Fig. 1C). The number of $\mathrm{UBD}^{+}$cells significantly increased in the NFT, TCP, and CBX groups, and significantly decreased in the ADAQ and TAT groups compared with untreated controls (Fig. 1D). The number of p-MDM2 $2^{+}$cells significantly decreased in the NFT, ADAQ, TCP, CP, and TAT groups compared with untreat- ed controls (Fig. 1E). The number of TUNEL ${ }^{+}$cells did not change in any of the treatment groups (Fig. 1F).

At day 7, the number of $\mathrm{Ki}-67^{+}$cells significantly increased in the NFT and TCP groups, and significantly decreased in the ADAQ and TAT groups compared with untreated controls (Fig. 2A). The number of p-Histone $\mathrm{H}^{+}$cells significantly increased in the NFT group, and significantly decreased in the $\mathrm{CP}$ group compared with untreated controls (Fig. 2B). The number of TOP $2 \mathrm{~A}^{+}$cells significantly increased in the TCP group, and significantly decreased in the ADAQ and TAT groups compared with untreated controls (Fig. 2C). The number of $\mathrm{UBD}^{+}$cells significantly increased in the TCP group, and significantly decreased in the ADAQ and TAT groups compared with untreated controls (Fig. 2D). The number of p-MDM2+ cells did not change in any of the treatment groups (Fig. 2E). The number of $\mathrm{TUNEL}^{+}$cells significantly increased in the NFT and TCP groups compared with untreated controls (Fig. 2F).

At day 28 , the number of $\mathrm{Ki}-67^{+}$cells significantly increased in the NFT, ADAQ, TCP, and CBX groups compared with untreated controls (Fig. 3A). The number of $\mathrm{p}$-Histone $\mathrm{H}^{+}$cells significantly increased in the NFT and CBX groups compared with untreated controls (Fig. 3B). The number of TOP2 $\mathrm{A}^{+}$cells significantly increased in the ADAQ, TCP, and CBX groups compared with untreated controls (Fig. $3 \mathrm{C}$ ). The number of $\mathrm{UBD}^{+}$ cells significantly increased in the ADAQ, TCP, and CBX groups compared with untreated controls (Fig. 3D). The number of p-MDM2+ cells significantly increased in the TCP group, and significantly decreased in the NFT and CP groups compared with untreated controls (Fig. 3E). The number of TUNEL ${ }^{+}$cells significantly increased in the CBX group compared with untreated controls (Fig. 3F).

\section{p-Histone $\mathrm{H}^{+} / \mathrm{Ki}-67^{+}$cell ratio}

To estimate the number of proliferative cells existing at $\mathrm{M}$ phase, the ratio of the number of $\mathrm{p}$-Histone $\mathrm{H}^{+}$cells to that of $\mathrm{Ki}-67^{+}$cells was calculated using data obtained from kidney slides immunohistochemically stained for each molecule in the same animal.

At day 3, the ratio of the number of p-Histone $\mathrm{H}^{+}$cells to that of $\mathrm{Ki}-67^{+}$cells significantly decreased in the TCP group compared with the untreated controls (Fig. 4A). At day 7 , the ratio of the number of $\mathrm{p}$-Histone $\mathrm{H} 3^{+}$cells to that of $\mathrm{Ki}-67^{+}$cells significantly decreased in the TCP group compared with untreated controls (Fig. 4B). At day 28 , the ratio of the number of $\mathrm{p}$-Histone $\mathrm{H}^{+}$cells to that of $\mathrm{Ki}-67^{+}$cells significantly decreased in the ADAQ and TCP groups compared with the untreated controls (Fig. 4C). 
M. Kimura et al.

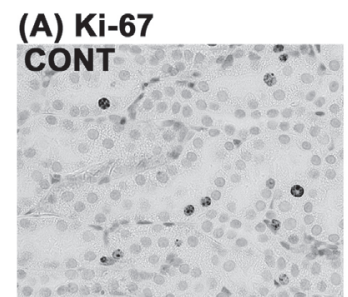

\section{(B) p-Hisotne H3}

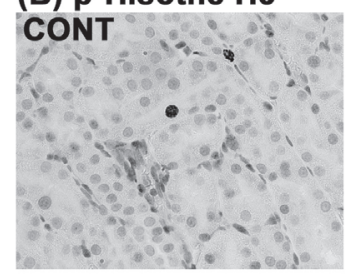

\section{(C) TOP2A}

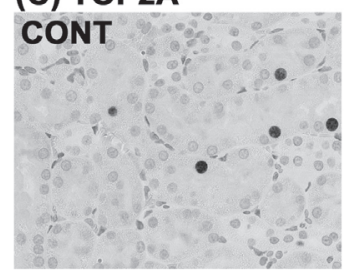

\section{(D) UBD}

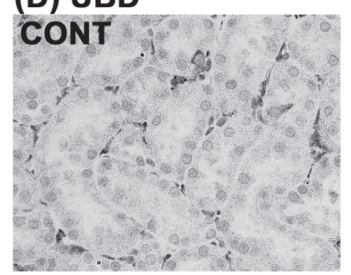

\section{(E) p-MDM2}

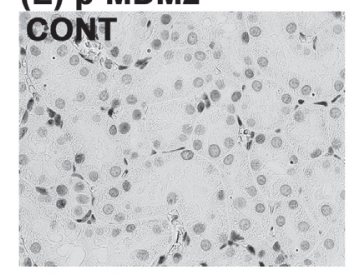

\section{(F) TUNEL}

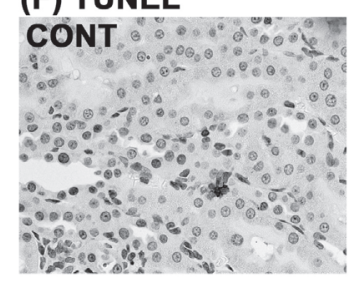

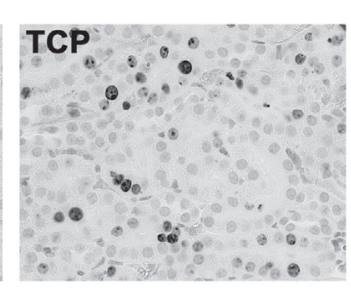
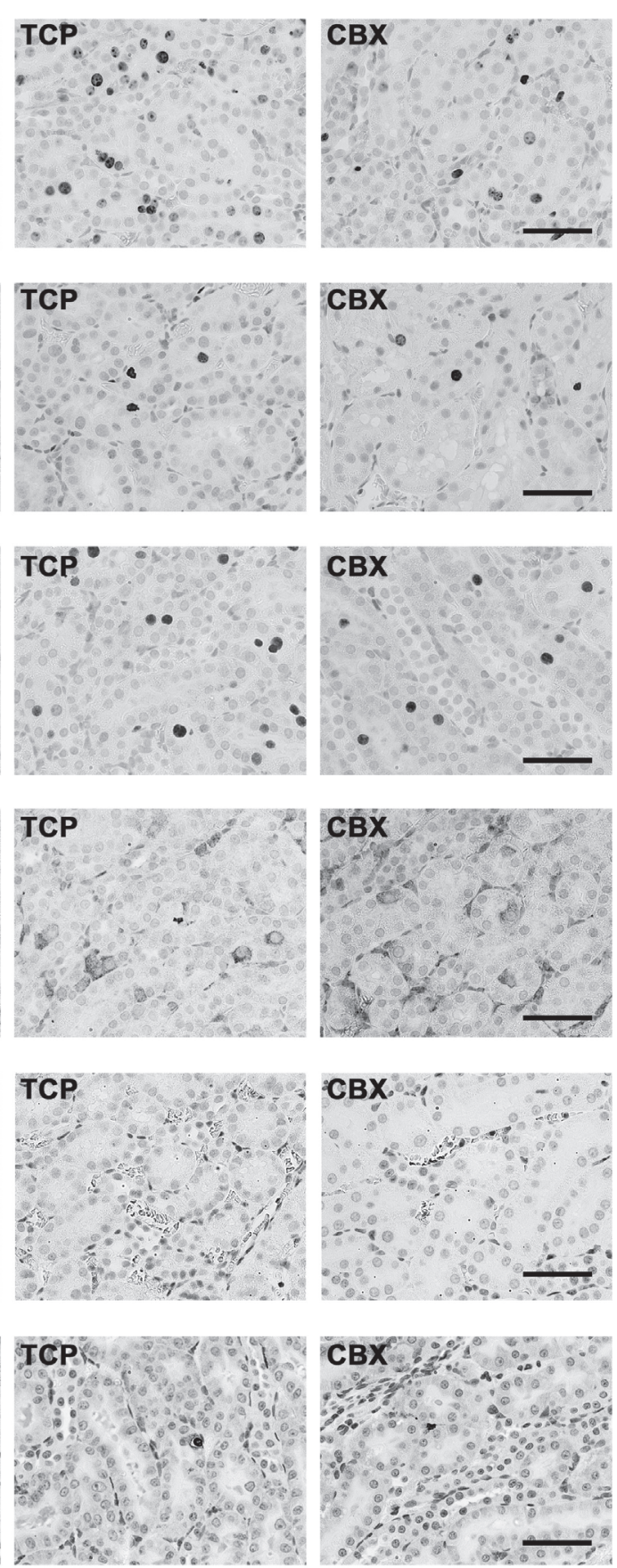
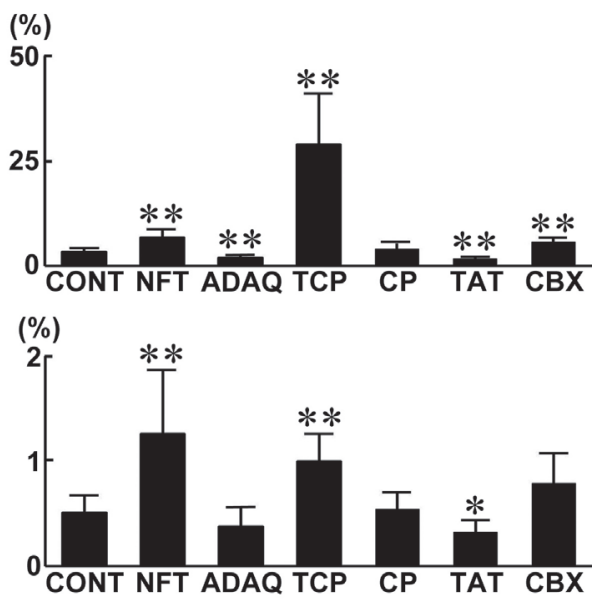

(\%)
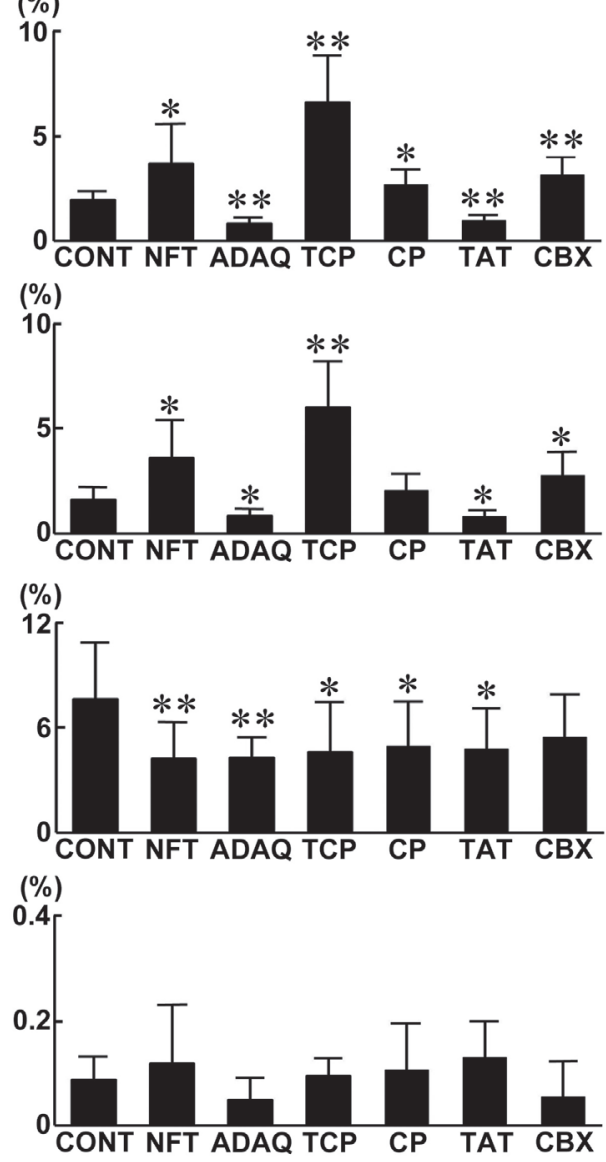

Fig. 1. Distribution of $\mathrm{Ki}-67^{+}$, p-Histone $\mathrm{H}^{+}$, $\mathrm{TOP}_{2} \mathrm{~A}^{+}, \mathrm{UBD}^{+}, \mathrm{p}-\mathrm{MDM} 2^{+}$, and TUNEL ${ }^{+}$cells in the OSOM of rats at day 3 after treatment with renal carcinogens or non-carcinogenic renal toxicants. Photomicrographs show the distribution of Ki- $67^{+}$, p-Histone $\mathrm{H}_{3}^{+}, \mathrm{TOP}_{2} \mathrm{~A}^{+}, \mathrm{UBD}^{+}, \mathrm{p}-\mathrm{MDM}^{+}$, and $\mathrm{TUNEL}^{+}$cells in the OSOM of representative cases from untreated controls and animals treated with TCP or CBX. The graphs show positive cell ratios of renal tubular epithelial cells per total cells counted in 10 animals of each group. Values represent mean + S.D. (A) Ki-67, (B) p-Histone H3, (C) TOP2A, (D) UBD, (E) p-MDM2, and (F) TUNEL. Bar $=50 \mu \mathrm{m}$. $* P<0.05, * * P<0.01$ vs. untreated controls (Dunnett's or Steel's test). 
Disruption of spindle checkpoint function by renal carcinogens in rats
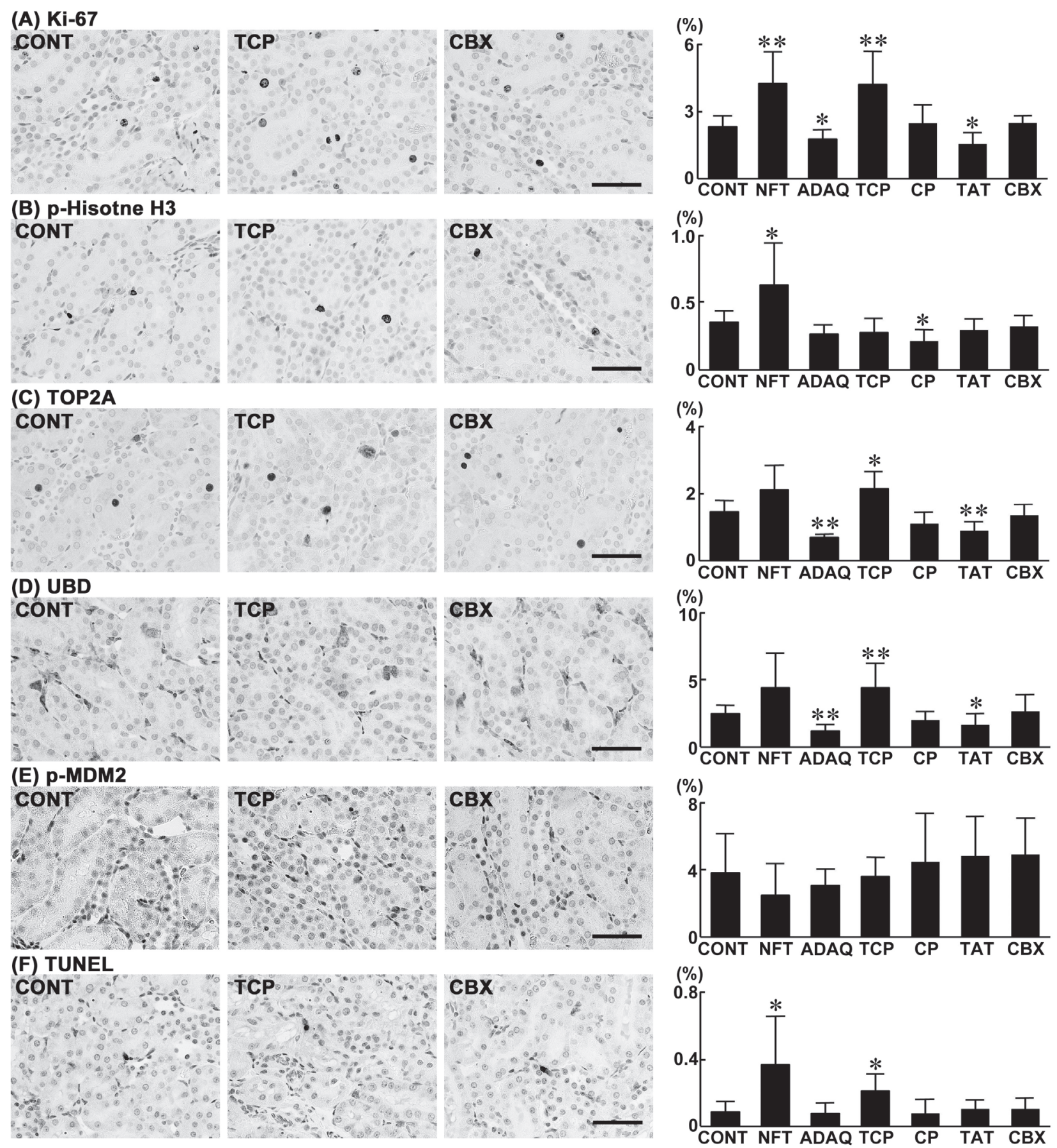

Fig. 2. Distribution of $\mathrm{Ki}-67^{+}$, p-Histone $\mathrm{H}^{+}, \mathrm{TOP} \mathrm{AA}^{+}, \mathrm{UBD}^{+}, \mathrm{p}-\mathrm{MDM}^{+}$, and $\mathrm{TUNEL}^{+}$cells in the OSOM of rats at day 7 after treatment with renal carcinogens or non-carcinogenic renal toxicants. Photomicrographs show the distribution of Ki-67+, p-Histone $\mathrm{H}^{+}$, $\mathrm{TOP}_{2} \mathrm{~A}^{+}, \mathrm{UBD}^{+}$, p-MDM2+, and $\mathrm{TUNEL}^{+}$cells in the OSOM of representative cases from untreated controls and animals treated with TCP or CBX. The graphs show positive cell ratios of renal tubular epithelial cells per total cells counted in 10 animals of each group. Values represent mean + S.D. (A) Ki-67, (B) p-Histone H3, (C) TOP2A, (D) UBD, (E) p-MDM2, and (F) TUNEL. Bar $=50 \mu \mathrm{m}$. $* P<0.05$, ** $P<0.01$ vs. untreated controls (Steel's test). 


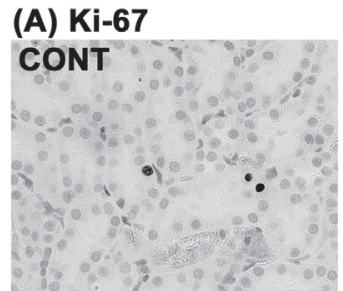

\section{(B) p-Hisotne H3}

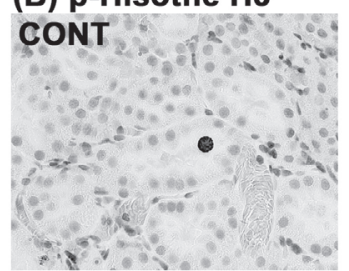

\section{(C) TOP2A}

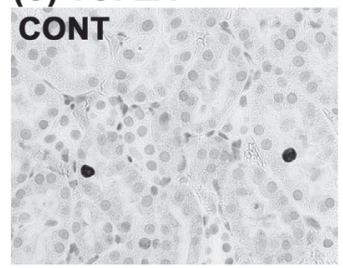

\section{(D) UBD}

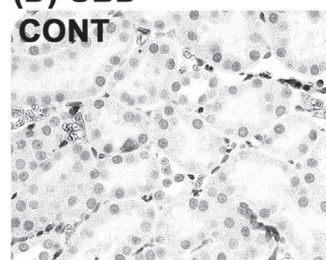

\section{(E) p-MDM2}

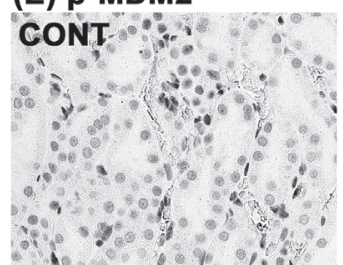

\section{(F) TUNEL}

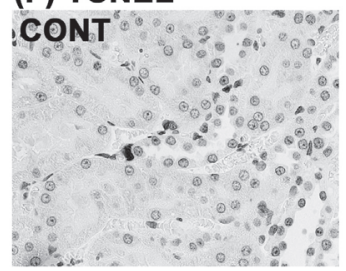

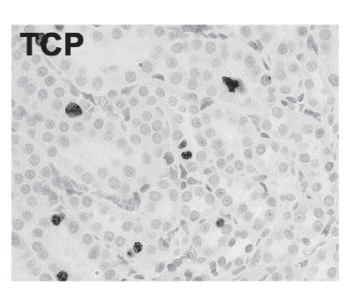
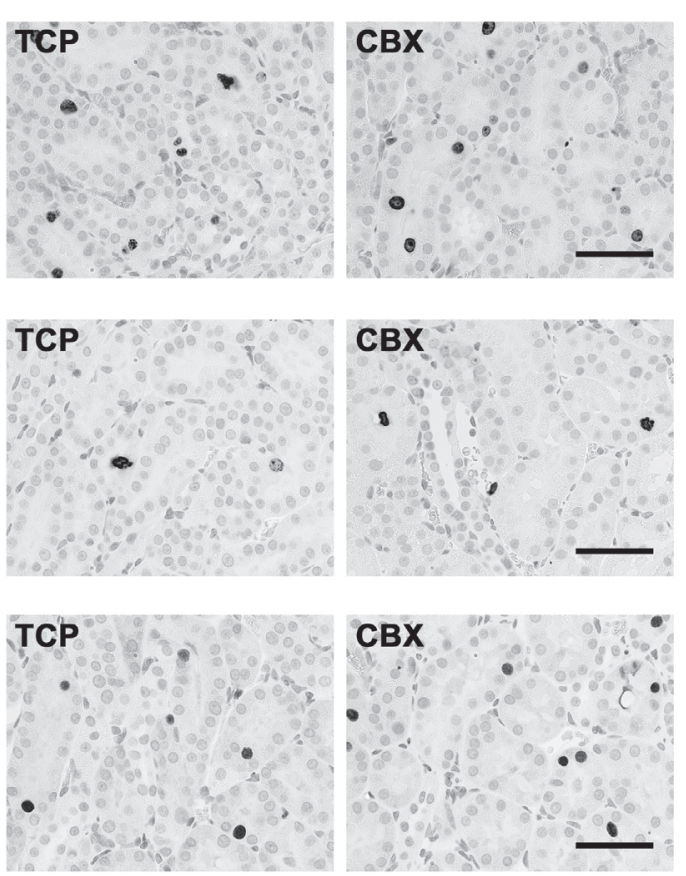

$$
\text { TCP: }
$$
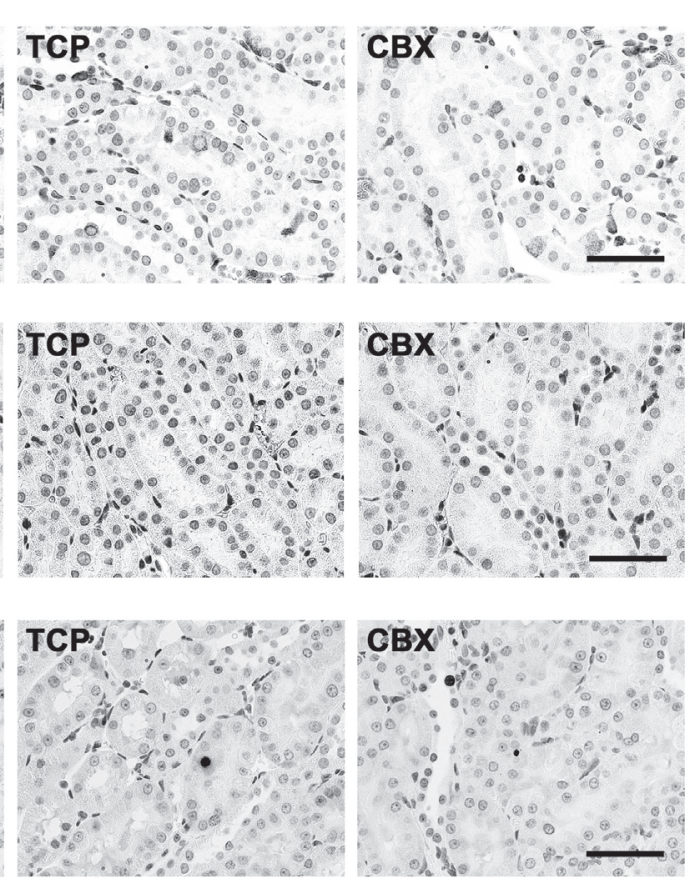

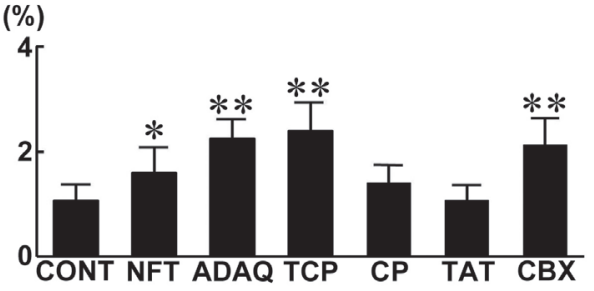

(\%)

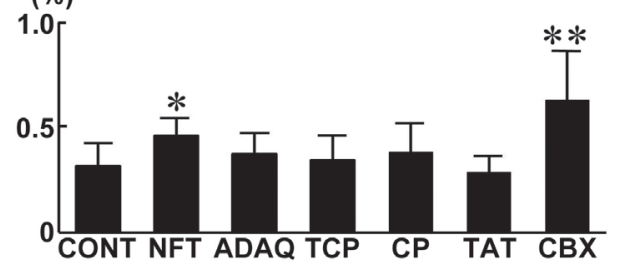

(\%)
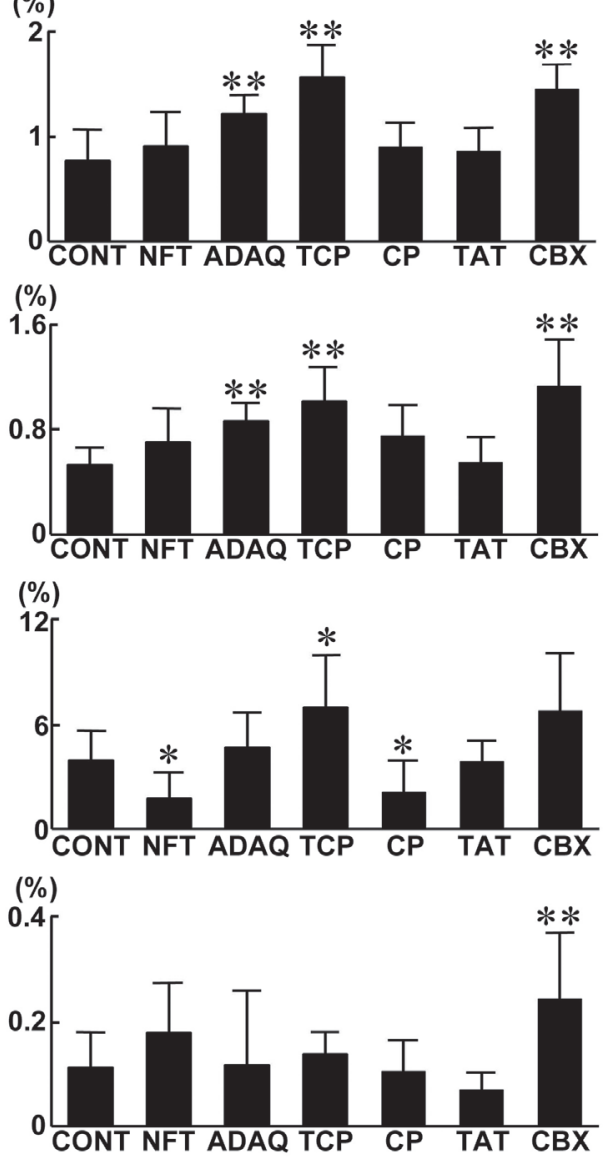

Fig. 3. Distribution of $\mathrm{Ki}-67^{+}$, p-Histone $\mathrm{H}^{+}$, $\mathrm{TOP}_{2} \mathrm{~A}^{+}, \mathrm{UBD}^{+}, \mathrm{p}-\mathrm{MDM} 2^{+}$, and $\mathrm{TUNEL}^{+}$cells in the OSOM of rats at day 28 after treatment with renal carcinogens or non-carcinogenic renal toxicants. Photomicrographs show the distribution of Ki-67+, p-Histone $\mathrm{H}^{+}$, $\mathrm{TOP}_{2} \mathrm{~A}^{+}, \mathrm{UBD}^{+}$, p-MDM2+, and $\mathrm{TUNEL}^{+}$cells in the OSOM of representative cases from untreated controls and animals treated with TCP or CBX. The graphs show positive cell ratios of renal tubular epithelial cells per total cells counted in 10 animals of each group. Values represent mean + S.D. (A) Ki-67, (B) p-Histone H3, (C) TOP2A, (D) UBD, (E) p-MDM2, and (F) TUNEL. Bar $=50 \mu \mathrm{m} .{ }^{*} P<0.05,{ }^{*} P<0.01$ vs. untreated controls (Dunnett's or Steel's test). 
Disruption of spindle checkpoint function by renal carcinogens in rats

(A) Day 3

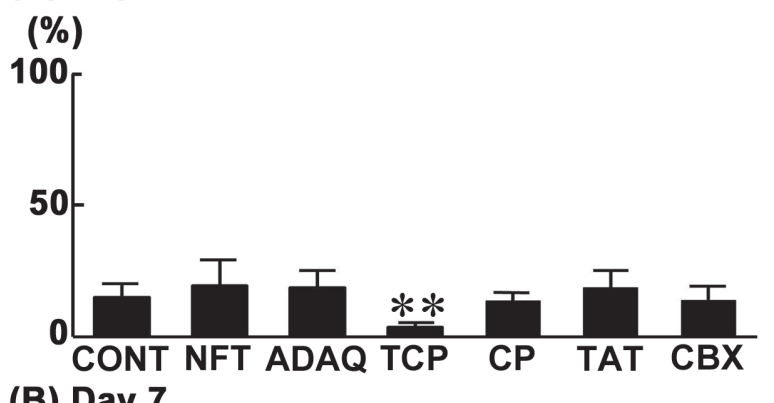

(B) Day 7

(\%)

100

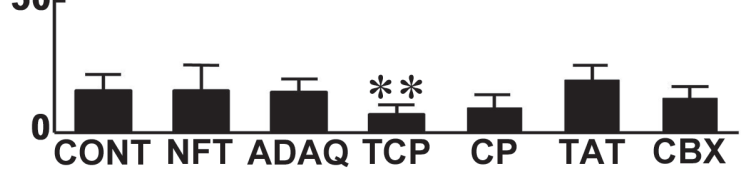

(C) Day 28

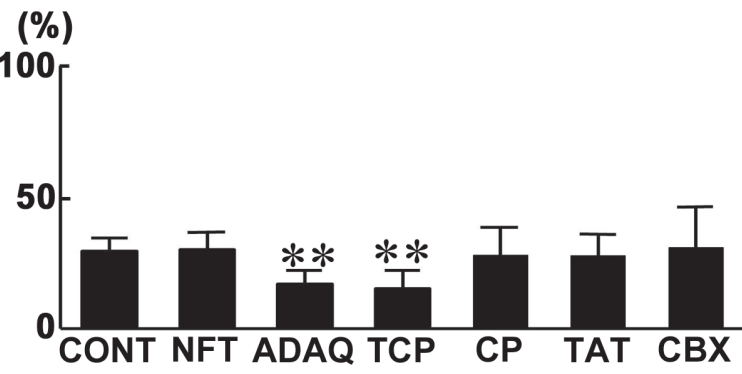

Fig. 4. p-Histone $\mathrm{H} 3^{+} / \mathrm{Ki}-67^{+}$cell ratio in the OSOM of rats at days 3, 7 and 28 after treatment with renal carcinogens or non-carcinogenic renal toxicants. The graphs show the p-Histone $\mathrm{H}^{+}$cell ratio of renal tubular epithelial cells per number of $\mathrm{Ki}-67^{+}$cells counted in 10 animals of each group. Values represent mean + S.D. (A) Day 3, (B) Day 7 and (C) Day 28. ** $P<0.01$ vs. untreated controls (Steel's test).

\section{Colocalization of UBD with TOP2A or p-Histone H3}

At day 3, the ratio of TOP2 $\mathrm{A}^{+}$cells to the total number of $\mathrm{UBD}^{+}$cells did not change in any of the treatment groups (Fig. 5A). In contrast, the ratio of p-Histone $\mathrm{H}^{+}$ cells to the total number of UBD + cells significantly decreased in the TCP and CBX groups compared with the untreated controls (Fig. 5B).

At day 7, the ratio of TOP $2 \mathrm{~A}^{+}$cells to the total number of $\mathrm{UBD}^{+}$cells significantly increased in the TCP group compared with the untreated controls (Fig. 5C). The ratio of p-Histone $\mathrm{H}^{+}$cells to the total number of $\mathrm{UBD}^{+}$cells significantly decreased in the TCP group compared with the untreated controls (Fig. 5D).

At day 28 , the ratio of TOP $2 \mathrm{~A}^{+}$cells to the total number of the $\mathrm{UBD}^{+}$cells did not change in any of the treatment group (Fig. 5E). The ratio of p-Histone $\mathrm{H}^{+}$cells to the total number of $\mathrm{UBD}^{+}$cells significantly decreased in the ADAQ and TCP groups compared with untreated controls (Fig. 5F).

\section{Real-time RT-PCR analysis}

Transcript levels of the genes listed in Supplementary Table 2 at days 3, 7 and 28 of treatment were determined by real-time RT-PCR in the NFT, ADAQ, TCP, and CBX groups, and compared with the levels in untreated controls (Supplementary Table 3).

At day 3, transcript levels of Cdknla (cyclin-dependent kinase inhibitor 1A) after normalization to Actb and/ or Gapdh levels significantly increased in all treatment groups compared with untreated controls. Transcript levels of Chek1 (checkpoint kinase 1) and Mad2l1 (MAD2 mitotic arrest deficient-like 1 [yeast]) after normalization to $A c t b$ and/or Gapdh levels significantly increased in the NFT, TCP, and CBX groups, and significantly decreased in the ADAQ group compared with untreated controls. Transcript levels of Mdm2 (MDM2 proto-oncogene, E3 ubiquitin protein ligase) after normalization to Actb and Gapdh levels significantly increased in the ADAQ, TCP, and CBX groups, and transcript levels of $M d m 2$ after normalization to Gapdh levels significantly decreased in the NFT group compared with untreated controls. Transcript levels of Rbl2 (retinoblastoma-like 2) after normalization to Actb levels significantly increased in the NFT and TCP groups compared with untreated controls. Transcript levels of $T p 53$ (tumor protein p53) after normalization to $A c t b$ and/or Gapdh levels significantly increased in the TCP and CBX groups, and transcript levels of Tp53 after normalization to Gapdh levels significantly decreased in the NFT group compared with untreated controls.

At day 7, transcript levels of Cdkn la, Chek1, and Mad2ll after normalization to Actb and/or Gapdh levels significantly increased in the NFT and TCP groups compared with untreated controls. Transcript levels of $C d k n 1 a$ and Mad2l1 after normalization to Actb and/or Gapdh levels significantly decreased in the ADAQ group compared with untreated controls. Transcript levels of $M d m 2$ after normalization to Actb and/or Gapdh levels significantly increased in the ADAQ, TCP, and CBX groups compared with untreated controls. Transcript levels of $T p 53$ after normalization to $A c t b$ and/or Gapdh levels significantly increased in all treatment groups compared with untreated controls. Transcript levels of $R b l 2$ after normalization 
(A) TOP2A/UBD (Day 3)

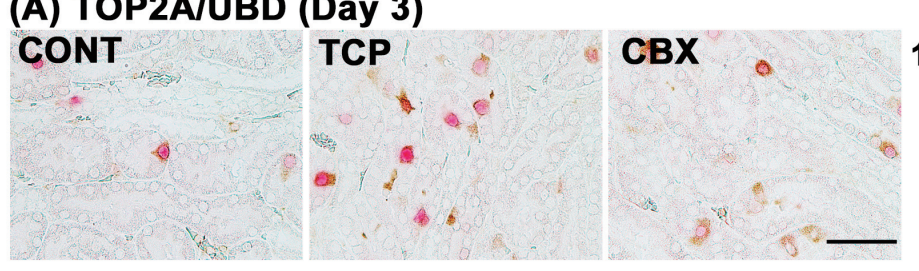

(B) p-Histone H3/UBD (Day 3) CONT

TCP

a

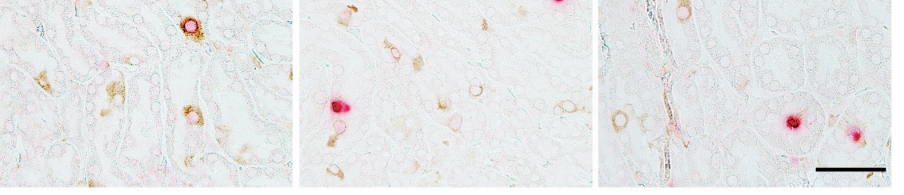

(C) TOP2A/UBD (Day 7)

CONT

TCP

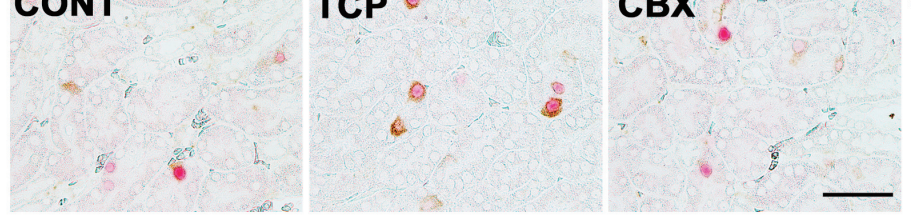

(D) p-Histone H3/UBD (Day 7)

CONT

TCP
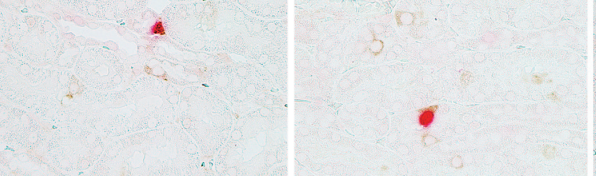

(E) TOP2A/UBD (Day 28)

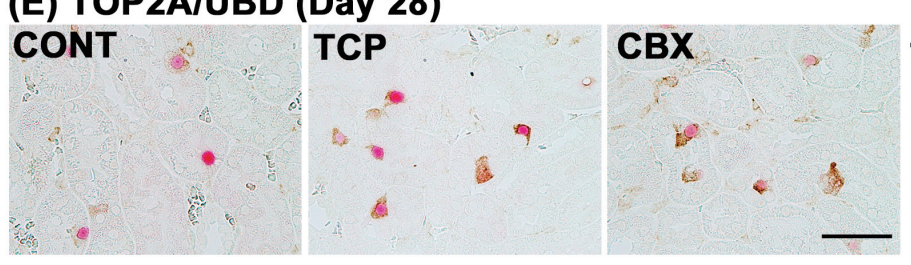

(F) p-Histone H3/UBD (Day 28)

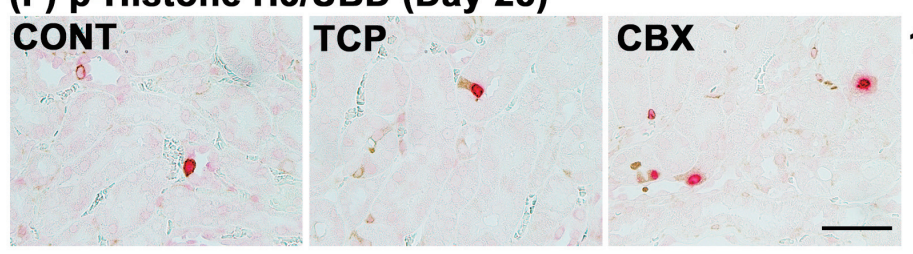

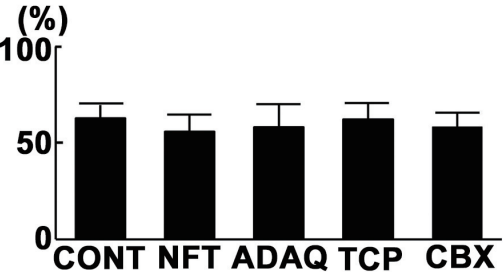

(\%)

100

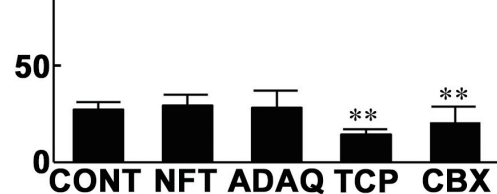

(\%)

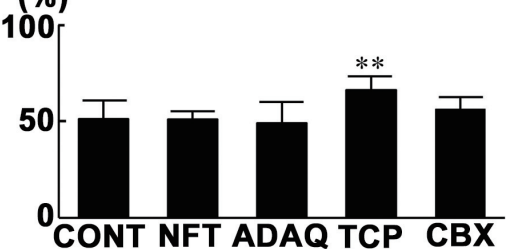

(\%)

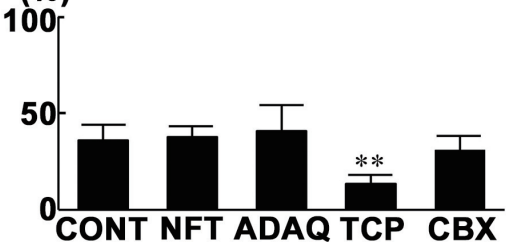

(\%)
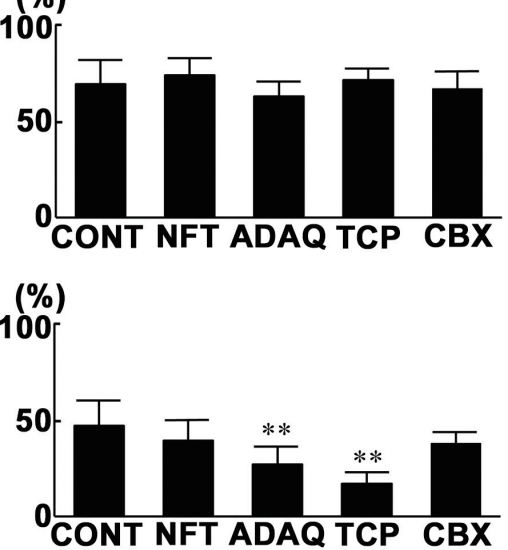

Fig. 5. Distribution of cell populations co-expressing UBD and TOP2A (TOP2A/UBD) or UBD and p-Histone H3 (p-Histone H3/ UBD) in the OSOM of rats at days 3, 7 and 28. Photomicrographs show the distribution of TOP2A/UBD and p-Histone H3/ UBD in the OSOM of representative cases from untreated controls and animals treated with TCP or CBX. The immunoreactivity of UBD (cytoplasm), and TOP2A (nucleus) or p-Histone H3 (nucleus) is visualized as brown and red, respectively. The graphs show the TOP2A or p-Histone H3-positive cell ratio (\%) per total renal tubular epithelial cells immunoreactive to UBD counted in 10 animals of each group. Values represent mean + S.D. (A) TOP2A/UBD (day 3), (B) p-Histone H3/ UBD (day 3), (C) TOP2A/UBD (day 7), (D) p-Histone H3/UBD (day 7), (E) TOP2A/UBD (day 28), and (F) p-Histone H3/ UBD (day 28). Bar $=50 \mu \mathrm{m}$. ** $P<0.01$ vs. untreated controls (Dunnett's or Steel's test). 
Disruption of spindle checkpoint function by renal carcinogens in rats

to Actb levels significantly increased in the ADAQ, TCP, and CBX groups, and transcript levels of Rbl2 after normalization to Gapdh levels significantly decreased in the NFT group compared with untreated controls.

At day 28, transcript levels of Cdknla after normalization to Actb and Gapdh levels significantly increased in the TCP group, and significantly decreased in the ADAQ group compared with untreated controls. Transcript levels of Chek1 after normalization to Actb and/or Gapdh levels significantly increased in the NFT, TCP, and CBX groups compared with untreated controls. Transcript levels of Mad2l1 after normalization to Actb and/or Gapdh levels significantly increased in the ADAQ, TCP, and CBX groups compared with untreated controls. Transcript levels of $M d m 2$ and Tp53 after normalization to Actb and/or Gapdh levels significantly increased in the ADAQ, TCP, and CBX groups compared with untreated controls. Transcript levels of Mdm2 after normalization to Gapdh levels significantly decreased in the NFT group compared with untreated controls. Transcript levels of Rbl2 after normalization to Actb levels significantly increased in the TCP group, and transcript levels of Rbl2 after normalization to Gapdh levels significantly decreased in the NFT group compared with untreated controls.

\section{DISCUSSION}

We have previously reported that 28-day administration of carcinogens facilitating cell proliferation induces an increase in immunoreactive cell populations for cellcycle-related molecules and apoptosis irrespective of the target organ (Kimura et al., 2015a; Taniai et al., 2012a, 2012b; Yafune et al., 2013a, 2013b). In the present study, the renal carcinogens NFT and TCP increased in the number of $\mathrm{Ki}-67^{+}$cells and cells immunoreactive for cellcycle-related molecules 3 days after administration, and renal carcinogen ADAQ induced increases at day 28. The non-carcinogenic renal toxicant $\mathrm{CBX}$ also showed similar cellular responses at days 3 and 28 . We also previously reported that the non-carcinogenic hepatotoxicant promethazine facilitated cell proliferation and showed a similar pattern of increase in cell populations immunoreactive for cell-cycle proteins to that of the hepatocarcinogenic methyleugenol and thioacetamide in the liver (Kimura et al., 2015a). In addition, the number of TUNEL ${ }^{+}$cells increased in NFT and TCP groups transiently at day 7 , and only in the CBX group at day 28 , indicating that a carcinogen-specific response was not observed with regard to apoptosis. These results suggest that increases in the expression of cell-cycle proteins and apoptosis may not be a carcinogen-specific cellular response, and that it may be difficult to detect carcinogen-specific responses by simple analysis of immunoreactive cell populations and apoptosis using a time-course study of 3, 7 and 28 days of administration.

We have previously reported that 28-day administration of hepatocarcinogens upregulated the spindle checkpoint gene Mad2l1 (Weaver and Cleveland, 2005), the $\mathrm{G}_{2} / \mathrm{M}$ checkpoint gene Chek1 (Patil et al., 2013), Cdkn1a encoding p $21^{\mathrm{Cip} 1}$, and downregulated Rbl2, a gene encoding $\mathrm{RB}$ family protein that regulates the progression of $\mathrm{G}_{1} / \mathrm{S}$ phase (Cobrinik et al., 1996; Cobrinik, 2005), suggestive of an increase in $G_{2}$ and $M$ phase-arrested hepatocyte populations and disruption of $\mathrm{G}_{1} / \mathrm{S}$ checkpoint function by hepatocarcinogens (Kimura et al., 2015a). However, in a time course administration study of hepatocarcinogens and hepatocarcinogenic promoters for up to 90 days, expression of Mad2l1, Chek1, Cdkn1a, and Rbl2 mRNA lacked specificity to carcinogens (Kimura et al., 2015b). In the present study, renal carcinogens also did not induce carcinogen-specific expression changes of these genes in any time points. These results suggest that upregulation of Mad2l1, Chek1, and Cdkn1a, and downregulation of Rbl2 mRNA may not be responsible for carcinogenesis at early stage of repeated administration of carcinogens.

In the present study, renal carcinogens ADAQ and TCP and non-carcinogenic renal toxicant $\mathrm{CBX}$ upregulated transcript levels of $M d m 2$ and Tp53 3 days after administration, with the exception of $T p 53$ expression in the ADAQ group at day 3. p53 is known to regulate multiple genes against acute kidney injury, and MDM2 acts as a regulator of $\mathrm{p} 53$ function via ubiquitination and proteasomal degradation or retention of inactive p53 in the cytosol (McNicholas and Griffin, 2012). The MDM2 protein is regulated by multisite phosphorylation, and the phosphorylated site determines the function of MDM2 (Meek and Hupp, 2010). In human hepatocellular carcinoma and lung carcinoma cell lines, it is reported that phosphorylation of MDM2 at Ser 166 is induced by growth factor-mediated signaling, which leads to translocation of MDM2 from the cytoplasm to the nucleus for facilitation of p53 degradation (Malmlöf et al., 2007; Mayo and Donner, 2002). Furthermore, it is reported that human breast cancers showed high expression of MDM2 phosphorylation at Ser 166 in association with cell proliferation activity and a poor prognosis (Schmitz et al., 2006). We previously reported that hepatocarcinogens specifically increased transcript levels of $M d m 2$ and/or MDM2 ${ }^{+}$cells phosphorylated at Ser 166, suggestive of facilitation of degradation of p53 and subsequent disruption of $\mathrm{G}_{1} / \mathrm{S}$ checkpoint function by hepatocarcinogen treatment (Kimura et al., 
2015a, 2015b). However, in the present study, we did not observe a carcinogen-specific increase in p-MDM2 $2^{+}$cells phosphorylated at Ser 166 by renal carcinogens, while mRNA upregulation of $M d m 2$ was found with these carcinogens, as with non-carcinogenic renal toxicant CBX from day 3. These results suggest that upregulation of $M d m 2$ may be caused by upregulation of p53 in response to the nephrotoxic effects of both renal carcinogens and non-carcinogenic renal toxicants. The lack of induction of phosphorylation of MDM2 at Ser 166 at the early stages of renal carcinogen administration may be responsible for the lack of cell proliferation facilitation, which is different from the hepatocarcinogens.

It is reported that overexpression of UBD suppresses the kinetochore localization of MAD2, a spindle checkpoint molecule, during the $\mathrm{M}$ phase, which may eventually lead to chromosomal instability (Herrmann et al., 2007; Lim et al., 2006). It has also been reported that the UBDMAD2 interaction reduces the proliferating cell population at $\mathrm{M}$ phase, reflecting spindle checkpoint disruption (Theng et al., 2014). We have previously reported that 28- or 90-day administration of carcinogens irrespective of their potential to induce facilitation of cell proliferation causes aberrant expression of UBD at the $\mathrm{G}_{2}$ phase and a reduction in the ratio of proliferative cells existing at the $\mathrm{M}$ phase, indicating disruption of spindle checkpoint function (Kimura et al., 2015a, 2015b; Taniai et al., 2012b). In the present study, the renal carcinogens ADAQ and TCP facilitated cell proliferation and also reduced the ratio of $\mathrm{UBD}^{+}$cells coexpressing $\mathrm{p}$-Histone $\mathrm{H} 3$ to the total number of $\mathrm{UBD}^{+}$cells and the ratio of $\mathrm{p}$-Histone $\mathrm{H}^{+}$cells to that of $\mathrm{Ki}-67^{+}$cells at day 28 . In contrast, the non-carcinogenic renal toxicant $\mathrm{CBX}$ only temporarily reduced $\mathrm{UBD}^{+}$cells coexpressing p-Histone $\mathrm{H} 3$ at day 3 , but without the accompanied reduction in the ratio of $\mathrm{p}$-Histone $\mathrm{H} 3^{+}$cells to that of $\mathrm{Ki}-67^{+}$cells. Because p-Histone $\mathrm{H} 3$ is an M phase protein (Hirota et al., 2005), these results suggest that renal carcinogens may cause insufficient UBD expression at the $M$ phase, probably in conjunction with the early transition of proliferating cells from the $\mathrm{M}$ phase at day 28 , in contrast to no such response with non-carcinogenic renal toxicants. Therefore, disruption of spindle checkpoint function may be a key event for carcinogenesis at early stage of repeated administration of carcinogens, and it may take 28 days to induce disruption of spindle checkpoint function by renal carcinogens. On the other hand, TCP also decreased $\mathrm{UBD}^{+}$cells at $M$ phase at day 7 of administration, while other renal carcinogens did not induce similar cellular responses at this time point. TCP also decreased proliferating cells at $\mathrm{M}$ phase at this time point, suggesting that TCP may disrupt spindle checkpoint function at the time point as early as day 7 of administration.

In contrast to ADAQ and TCP, the renal carcinogen NFT did not show a reduction in the number of $\mathrm{UBD}^{+}$ cells coexpressing $\mathrm{p}$-Histone $\mathrm{H} 3$ and in the ratio of p-Histone $\mathrm{H}^{+}$cells to that of $\mathrm{Ki}-67^{+}$cells at any time point in the present study, while NFT facilitated cell proliferation activity at all time points. It is reported that a 2-year carcinogenicity study on NFT using rats induced a marginal, but significant, increase in the incidence of renal tubular neoplasms as assessed using additional step-sections of the left and right kidney from each rat; however, the increase was not initially detected after the evaluation using standard single sections (NTP, 1989), suggestive of marginal renal carcinogenic potential of NFT. Both ADAQ and TCP apparently increased the incidence of renal tumors in their 2-year carcinogenicity studies (NTP, 1993a; NTP, 1996). We have reported that leucomalachite green exerting marginal hepatocarcinogenicity did not reduce the ratio of $\mathrm{p}$-Histone $\mathrm{H}^{+}{ }^{+}$cells to that of $\mathrm{Ki}-67^{+}$ cells by repeated administration for up to 90 days (Kimura et al., 2015b). Therefore, disruption of spindle checkpoint function may not be induced by renal carcinogens exerting marginal carcinogenicity. Cell-cycle facilitation by NFT may be a reflection of the toxic effect of NFT on renal tubules in the present study.

We have previously found that renal carcinogens are associated with development of nephropathy or karyomegaly without relation to genotoxic potentials in a review of the results of carcinogenicity bioassays by the NTP (Taniai et al., 2012a). Among renal carcinogens tested in the present study, repeated administration of ADAQ or TCP to rats has been shown to induce karyomegaly in renal tubular cells (NTP, 1993a; NTP, 1996), while NFT has been shown to induce nephropathy (NTP, 1989). In the present study, NFT, which did not induce karyomegaly, did not cause disruption of spindle checkpoint function. These results may suggest that the ability to induce karyomegaly to carcinogenic target cells is involved in the induction of spindle checkpoint dysfunction. On the other hand, hepatocarcinogen CRB, which did not induce karyomegaly even after 90 days of administration, also caused disruption of spindle checkpoint function (Kimura et al., 2015b). Therefore, disruption of spindle checkpoint function may also be induced by renal carcinogens that do not cause karyomegaly in target tubular cells after repeated administration.

Because carcinogens may exert genotoxicity or trigger oxidative stress responses in relation with carcinogenesis, it is possible that these potentials are involved in disruption of spindle checkpoint function. With regard 
Disruption of spindle checkpoint function by renal carcinogens in rats

to the genotoxic potential of renal carcinogens used in the present study, previous reports suggested that NFT, ADAQ, and TCP are all categorized as genotoxic renal carcinogens (NTP, 1989; NTP, 1993a; NTP, 1996). It is also reported that NFT induced oxidative DNA damage to rat kidney after 28-day repeated oral administration of the carcinogenic dose level (Kijima et al., 2015). However, NFT did not cause disruption of spindle checkpoint function in the present study. These results suggest that it is difficult to find the relationship between the potential to induce spindle checkpoint dysfunction and genotoxic potential of renal carcinogens. Of note, we have shown disruption of spindle checkpoint function in liver cells after repeated 28-day administration of non-genotoxic hepatocarcinogens, i.e., thioacetamide and methapyrilene, in rats (Kimura et al., 2015a, 2015b; Omura et al., 2014). These results suggest that spindle checkpoint dysfunction may be caused by carcinogens without relationship to their genotoxic potential.

In conclusion, both renal carcinogens and non-carcinogenic renal toxicants facilitating cell proliferation increased the number of cells expressing cell-cycle proteins following treatment for up to 28 days, indicating the difficulty in predicting the carcinogenic potential of chemicals by immunohistochemical single molecule analysis in the framework of a 28-day toxicity study. By means of mRNA expression analysis, carcinogen-specific responses in the transcript expression of cell-cycle regulator genes were also lacking following treatment for up to 28 days, which differed from hepatocarcinogens. In contrast, the renal carcinogens ADAQ and TCP reduced the number of cells expressing UBD and the number of proliferating cells at the $\mathrm{M}$ phase, suggesting insufficient UBD expression at the $M$ phase and early transition of proliferating cells from $\mathrm{M}$ phase, but without the accompanied increase in apoptosis, after 28 days of administration. However, NFT, which has been shown to exert marginal carcinogenic potential, did not induce such cellular responses. These results suggest that it may take 28 days to induce spindle checkpoint dysfunction by renal carcinogens; however, induction of apoptosis may not be essential for this disruption. In contrast, marginal carcinogens may not exert sufficient responses even after 28 days of administration. Further studies may be necessary on the mechanism playing a role for the disruption of spindle checkpoint functions, especially in terms of the molecular interaction of UBD and other regulator molecules after repeated administration of carcinogens.

\section{ACKNOWLEDGMENTS}

The authors thank Mrs. Shigeko Suzuki for her technical assistance in preparing the histological specimens. This work was supported by Health and Labour Sciences Research Grants (Research on Food Safety) from the Ministry of Health, Labour and Welfare of Japan (Grant No. H25-shokuhin-ippan-005). M.K. is a Research Fellow of the Japan Society for the Promotion of Science.

Conflict of interest---- The authors declare that there is no conflict of interest.

\section{REFERENCES}

Cobrinik, D., Lee, M.H., Hannon, G., Mulligan, G., Bronson, R.T., Dyson, N., Harlow, E., Beach, D., Weinberg, R.A. and Jacks, T. (1996): Shared role of the pRB-related p130 and p107 proteins in limb development. Genes Dev., 10, 1633-1644.

Cobrinik, D. (2005): Pocket proteins and cell cycle control. Oncogene, 24, 2796-2809.

Eastin, W.C. (1998): The U.S. National toxicology program evaluation of transgenic mice as predictive models for identifying carcinogens. Environ. Health Perspect., 106, 81-84.

Herrmann, J., Lerman, L.O. and Lerman, A. (2007): Ubiquitin and ubiquitin-like proteins in protein regulation. Circ. Res., 100, 1276-1291.

Hirota, T., Lipp, J.J., Toh, B.H. and Peters, J.M. (2005): Histone H3 serine 10 phosphorylation by Aurora B causes HP1 dissociation from heterochromatin. Nature, 438, 1176-1180.

Jonker, M.J., Bruning, O., van Iterson, M., Schaap, M.M., van der Hoeven, T.V., Vrieling, H., Beems, R.B., de Vries, A., van Steeg, H., Breit, T.M. and Luijten, M. (2009): Finding transcriptomics biomarkers for in vivo identification of (non-)genotoxic carcinogens using wild-type and Xpa/p53 mutant mouse models. Carcinogenesis, 30, 1805-1812.

Kijima, A., Ishii, Y., Takasu, S., Matsushita, K., Kuroda, K., Hibi, D., Suzuki, Y., Nohmi, T. and Umemura, T. (2015): Chemical structure-related mechanisms underlying in vivo genotoxicity induced by nitrofurantoin and its constituent moieties in gpt delta rats. Toxicology, 331, 125-135.

Kimura, M., Abe, H., Mizukami, S., Tanaka, T., Itahashi, M., Onda, N., Yoshida, T. and Shibutani, M. (2015a): Onset of hepatocarcinogen-specific cell proliferation and cell cycle aberration during the early stage of repeated hepatocarcinogen administration in rats. J. Appl. Toxicol., DOI: 10.1002/jat.3163.

Kimura, M., Mizukami, S., Watanabe, Y., Hasegawa-Baba, Y., Onda, N., Yoshida, T. and Shibutani, M. (2015b): Disruption of spindle checkpoint function ahead of facilitation of cell proliferation by repeated administration of hepatocarcinogens in rats. J. Toxicol. Sci., 40, 855-871.

Lim, C.B., Zhang, D. and Lee, C.G. (2006): FAT10, a gene up-regulated in various cancers, is cell-cycle regulated. Cell Div., 1, 20.

Livak, K.J. and Schmittgen, T.D. (2001): Analysis of relative gene expression data using real-time quantitative PCR and the $2^{-\Delta \Delta C_{T}}$ method. Methods, 25, 402-408.

Malmlöf, M., Roudier, E., Högberg, J. and Stenius, U. (2007): MEK-ERK-mediated phosphorylation of Mdm2 at Ser-166 in 
hepatocytes. Mdm2 is activated in response to inhibited Akt signaling. J. Biol. Chem., 282, 2288-2296.

Matsumoto, H., Saito, F. and Takeyoshi, M. (2014): CARCINOscreen $^{\circledR}$ : New short-term prediction method for hepatocarcinogenicity of chemicals based on hepatic transcript profiling in rats. J. Toxicol. Sci., 39, 725-734.

Mattila, R., Alanen, K. and Syrjänen, S. (2007): Immunohistochemical study on topoisomerase II $\alpha, \mathrm{Ki}-67$ and cytokeratin-19 in oral lichen planus lesions. Arch. Dermatol. Res., 298, 381-388.

Mayo, L.D. and Donner, D.B. (2002): The PTEN, Mdm2, p53 tumor suppressor-oncoprotein network. Trends Biochem. Sci., 27, 462-467.

McNicholas, B.A. and Griffin, M.D. (2012): Double-edged sword: a 553 regulator mediates both harmful and beneficial effects in experimental acute kidney injury. Kidney Int., 81, 1161-1164.

Meek, D.W. and Hupp, T.R. (2010): The regulation of MDM2 by multisite phosphorylation - opportunities for molecular-based intervention to target tumours? Semin Cancer Biol., 20, 19-28.

NTP (1989): NTP Toxicology and Carcinogenesis Studies of Nitrofurantoin (CAS No. 67-20-9) in F344/N Rats and B6C3F1 Mice (Feed Studies). Natl. Toxicol. Program Tech. Rep. Ser., 341, $1-218$.

NTP (1993a): NTP Toxicology and Carcinogenesis of 1,2,3-Trichloropropane (CAS No. 96-18-4) in F344/N Rats and B6C3F1 Mice (Gavage Studies). Natl. Toxicol. Program Tech. Rep. Ser., 384, $1-348$.

NTP (1993b): NTP Toxicology and Carcinogenesis Studies of Triamterene (CAS No. 396-01-0) in F344/N Rats and B6C3F1 Mice (Feed Studies). Natl. Toxicol. Program Tech. Rep. Ser., 420, 1-367.

NTP (1996): NTP Toxicology and Carcinogenesis Studies of 1-Amino-2,4-Dibromoanthraquinone (CAS No. 81-49-2) in F344/N Rats and B6C3F1 Mice (Feed Studies). Natl. Toxicol. Program Tech. Rep. Ser., 383, 1-370.

NTP (1998): NTP Toxicology and Carcinogenesis Studies of 1-Chloro-2-propanol (Technical Grade) (CAS NO. 127-00-4) in F344/N Rats and B6C3F1 Mice (Drinking Water Studies). Natl. Toxicol. Program Tech. Rep. Ser., 477, 1-264.

Omura, K., Uehara, T., Morikawa, Y., Hayashi, H., Mitsumori, K., Minami, K., Kanki, M., Yamada, H., Ono, A. and Urushidani, T. (2014): Detection of initiating potential of non-genotoxic carcinogens in a two-stage hepatocarcinogenesis study in rats. J. Toxicol. Sci., 39, 785-794.
Patil, M., Pabla, N. and Dong, Z. (2013): Checkpoint kinase 1 in DNA damage response and cell cycle regulation. Cell. Mol. Life Sci., 70, 4009-4021.

Schmitz, K.J., Grabellus, F., Callies, R., Wohlschlaeger, J., Otterbach, F., Kimmig, R., Levkau, B., Schmid, K.W. and Baba, H.A. (2006): Relationship and prognostic significance of phospho-(serine 166)-murine double minute 2 and Akt activation in node-negative breast cancer with regard to p53 expression. Virchows Arch., 448, 16-23.

Scholzen, T. and Gerdes, J. (2000): The Ki-67 protein: from the known and the unknown. J. Cell. Physiol., 182, 311-322.

Tamano, S. (2010): Carcinogenesis risk assessment of chemicals using medium-term carcinogenesis bioassays. Asian Pac. J. Cancer Prev., 11, 4-5.

Taniai, E., Hayashi, H., Yafune, A., Watanabe, M., Akane, H., Suzuki, K., Mitsumori, K. and Shibutani, M. (2012a): Cellular distribution of cell cycle-related molecules in the renal tubules of rats treated with renal carcinogens for 28 days: relationship between cell cycle aberration and carcinogenesis. Arch. Toxicol., 86, 1453-1464.

Taniai, E., Yafune, A., Hayashi, H., Itahashi, M., Hara-Kudo, Y., Suzuki, K., Mitsumori, K. and Shibutani, M. (2012b): Aberrant activation of ubiquitin $\mathrm{D}$ at $\mathrm{G}_{2}$ phase and apoptosis by carcinogens that evoke cell proliferation after 28-day administration in rats. J. Toxicol. Sci., 37, 1093-1111.

Theng, S.S., Wang, W., Mah, W.C., Chan, C., Zhuo, J., Gao, Y., Qin, H., Lim, L., Chong, S.S., Song, J. and Lee, C.G. (2014): Disruption of FAT10-MAD2 binding inhibits tumor progression. Proc. Natl. Acad. Sci. U.S.A., 111, E5282-5291.

USEPA (2004): Reregistration Eligibility Decision for Carboxin. US. Environmental Protection Agency., Available at: http://www. epa.gov/pesticides/reregistration/REDs/0012red_carboxin.pdf.

Weaver, B.A. and Cleveland, D.W. (2005): Decoding the links between mitosis, cancer, and chemotherapy: The mitotic checkpoint, adaptation, and cell death. Cancer Cell, 8, 7-12.

Yafune, A., Taniai, E., Morita, R., Nakane, F., Suzuki, K., Mitsumori, K. and Shibutani, M. (2013a): Expression patterns of cell cycle proteins in the livers of rats treated with hepatocarcinogens for 28 days. Arch. Toxicol., 87, 1141-1153.

Yafune, A., Taniai, E., Morita, R., Hayashi, H., Suzuki, K., Mitsumori, K. and Shibutani, M. (2013b): Aberrant activation of $\mathrm{M}$ phase proteins by cell proliferation-evoking carcinogens after 28-day administration in rats. Toxicol. Lett., 219, 203-210. 